\title{
Nature versus Nurture in Frontotemporal Lobar Degeneration: the Interaction of Genetic Background and Education on Brain Damage
}

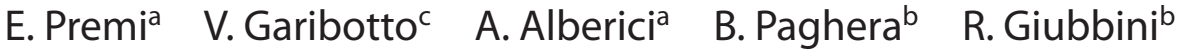 \\ A. Padovani ${ }^{\mathrm{a}}$ B. Borroni ${ }^{\mathrm{a}}$

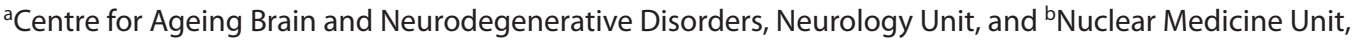 \\ University of Brescia, Brescia, Italy; ' Department of Medical Imaging, Geneva University Hospital, Geneva, \\ Switzerland
}

\section{Key Words}

Frontotemporal dementia - Cognitive reserve $\cdot$ Genetic

loading $\cdot$ SPECT $\cdot$ Statistical parametric mapping

\begin{abstract}
Background: Frontotemporal lobar degeneration (FTLD) is a progressive neurodegenerative disorder with a strong genetic background. It has been reported that modifiable factors, i.e. education (E), might act as proxies for reserve capacity. Objective: To evaluate the impact of genetic background (positive family history, $\mathrm{FH}$ ) on reserve mechanisms, by measuring regional cerebral blood flow (rCBF) correlates in FTLD patients. Methods: 145 FTLD patients were recruited and underwent clinical, neuropsychological, behavioral assessment, and SPECT study. The main effect of E and $\mathrm{FH}$ on $\mathrm{rCBF}$ was evaluated. To test the potential interaction between the $\mathrm{E}$ and $\mathrm{rCBF}$ in FTLD patients with or without positive $\mathrm{FH}$, a difference of slope analysis in the two groups was calculated. All the analyses were controlled for disease severity (Clinical Dementia Rating Scale, FTD-CDR). Results: $A$ main effect of education $(E+<E-)$ in frontal regions was reported, and high genetic loading $(\mathrm{FH}+<\mathrm{FH}-)$ was associ-
\end{abstract}

ated with a greater bilateral temporoparietal hypoperfusion. Evaluating the relationship between $\mathrm{E}$ and $\mathrm{rCBF}$, a greater hypoperfusion of cingulate region in $\mathrm{FH}+$ as compared to FH- was observed. Discussion: Reserve mechanisms are available also in presence of an unfavorable genetic status. However, these compensatory mechanisms are modulated by the interaction with genetic factors.

Copyright @ 2012 S. Karger AG, Basel

\section{Introduction}

Frontotemporal lobar degeneration (FTLD) is a progressive neurodegenerative disorder characteristically defined by behavioural changes, executive dysfunction and language deficits $[1,2]$. FTLD has a strong genetic background, as supported by positive family history in up to $40 \%$ of cases, higher than what reported in other neurodegenerative disorders and by the identification of causative genes related to the disease [3]. It has been suggested that genetic background might affect disease outcomes and rate of survival [4-8], modulating the onset

\section{KARGER \\ Fax +41613061234 \\ E-Mail karger@karger.ch}

www.karger.com
(C) 2012 S. Karger AG, Basel

1420-8008/12/0336-0372\$38.00/0

Accessible online at: www.karger.com/dem
Barbara Borroni, MD

Neurology Unit, University of Brescia

Piazza Spedali Civili 1

IT-25125 Brescia (Italy)

E-Mail bborroni@inwind.it 
and the progression of the pathological process when disease is overt.

Given the consolidated role of genetic loading in FTLD, the likely effect of environment has almost been neglected. Only recently, it has been reported that modifiable factors, i.e. education and occupation, might act as proxies for reserve capacity in FTLD. Patients with a high level of education and occupation can recruit an alternative neural network to cope better with cognitive functions [9-11].

This evidence suggests that both nonmodifiable and modifiable factors work and might interact in affecting disease aggressiveness and brain damage. Assessing their role is mandatory for a devastating condition still orphan of any evidence-based therapeutical intervention.

With these caveats in mind, in the present study we tested the influence of FTLD modifiable factors, i.e. educational attainment, and how these might be counteracted by the underneath unmodifiable genetic background, as measured by positive family history. Regional blood flow (rCBF) was used as in vivo proxy of FTLD pathological process, and the effect of each factor, separately, as well as their interaction, were evaluated.

\section{Methods}

\section{Subjects}

Patients fulfilling current clinical criteria for FTLD (bvFTD, PNFA, SD) $[1,12,13]$ were evaluated at the Centre for Aging Brain and Neurodegenerative Disorders, University of Brescia, Italy. To be eligible for the present study, FTLD patients had to undergo single-photon emission computed tomography (SPECT) imaging (all the SPECT done on the same scanner).

Each patient underwent clinical evaluation, a routine laboratory examination (including genetic screening for Microtuble Associated Protein Tau and Granulin mutations), and a brain structural imaging study. An extensive cognitive assessment according to a standardized battery was accomplished, as already reported [14]. The disease status was considered according to the Frontotemporal Dementia-modified Clinical Dementia Rating scale (FTD-modified CDR) [15].

Demographic characteristics, including years of schooling and medical family history, were carefully recorded. Years of schooling were defined as the number of completed years of formal education, including university; apprenticeship was considered only when associated to formal education. Patients with a positive family history as index of a genetic loading were those who had at least a first-degree relative with a documented diagnosis of dementia, parkinsonism, or motor neuron disease.

Stringent exclusion criteria were applied as follows: (a) cerebrovascular disorders, previous stroke, hydrocephalus, and intracranial mass documented by MRI; (b) a history of trau- matic brain injury or another neurological disease; (c) significant medical problems; (d) major depressive disorder, bipolar disorder, schizophrenia, substance abuse disorder, or mental retardation according to criteria of the DSM-IV; (e) lacking of demographic information.

The work was conformed to the Helsinki Declaration and was approved by the local Ethic Committee of Brescia Hospital, Italy.

\section{${ }^{99 m}$ Tc-ECD SPECT Acquisition Image Pre-Processing and \\ Analysis}

FTLD patients were administered an intravenous injection of $1,110 \mathrm{MBq}{ }^{99 m} \mathrm{Tc}-\mathrm{ECD}$ (ethylcysteinate dimer, Neurolite, Bristol-Myers Squibb Pharma) with closed eyes in a rest condition, lying supine in a quiet, dimlylit room. All individuals were imaged using a dual-head rotating gamma camera (VG MILLENIUM GE) fitted with a low energy, high-resolution collimator, 30 min after intravenous injection of ${ }^{99 \mathrm{~m}}$ Tc-ECD. A $128 \times 128$ pixel matrix was used for image acquisition with 120 views over a $360^{\circ}$ orbit (in $3^{\circ}$ step) with a pixel size and slice thickness of $1 \mathrm{~mm}$, in $27 \mathrm{~min}$ or more if total counts were lower than $5 \times 10^{6}$. Image reconstruction was performed by a ramp filtered-back projection and three-dimensionally smoothed with a Metz filter (order 3, enhancement 1.24, FWHM $6.7 \mathrm{~mm}$,

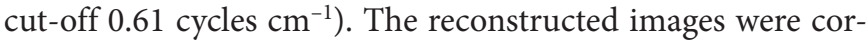
rected for gamma ray attenuation using the Chang method (attenuation coefficient: $\left.0.11 \mathrm{~cm}^{-1}\right)$.

Statistical Parametric Mapping (SPM8, Welcome Department of Cognitive Neurology, University College, London, UK), and Matlab 7.6 (Mathworks Inc., Sherborn, Mass., USA) were used for image pre-processing. Images were spatially normalized to a reference stereotactic template (Montreal Neurological Institute, $\mathrm{MNI}$ ), and smoothed by a Gaussian kernel of $8 \times 8 \times 8 \mathrm{~mm}$ FWHM. In all the analyses, dementia severity (as measured by FTD-modified CDR) was included as covariate.

\section{Statistical Analysis}

Patients were grouped according to years of schooling (E), considering a cut-off of 5 years [16] (high education, E+; low education, E-), and family history (FH) (negative family history, $\mathrm{FH}-$; positive family history, $\mathrm{FH}+$ ). The main effect of $\mathrm{E}$ and $\mathrm{FH}$ was evaluated $(\mathrm{p}<0.005$, extension threshold set at 30 contiguous voxels).

Brain areas related to cognitive reserve (namely medial frontal gyri, left superior and inferior frontal gyrus, left cingulate gyrus) were used to build up an a priori mask (Talairach Demon Database (WFU PickAtlas 3.0) $[17,18]$ ) to test the interaction of genetic loading on cognitive reserve. The residual main effect of $\mathrm{E}$ on $\mathrm{rCBF}$ after adjusting for $\mathrm{FH}$ was tested. Furthermore, analysis of covariance to test a possible additive effect of $\mathrm{E}$ and $\mathrm{F}$ was performed.

In order to test specifically for the relationship between $\mathrm{E}$ and $\mathrm{rCBF}$ in patients with and without $\mathrm{FH}$, we included all subjects' scans in the same design matrix, and tested for difference in the correlation coefficient value (slope) in the two groups [19]. For this latter analysis, in order to increase the sensitivity, findings meeting a threshold of $\mathrm{p}<0.05$, uncorrected for mul- 
Table 1. Results of the main effect of education and family history on $\mathrm{rCBF}$ in FTLD patients

\begin{tabular}{lllllllll}
\hline & $x$ & $y$ & $z$ & $T$ & $p$ & $\begin{array}{llll}\text { Cluster } \\
\text { size }\end{array}$ \\
\hline
\end{tabular}

\section{Education}

$\begin{array}{lrrrrrr}\text { R medial frontal gyrus } & 26 & 38 & 20 & 3.72 & <0.001 & 505 \\ \text { L superior frontal gyrus } & -22 & 54 & 6 & 3.36 & 0.001 & 159 \\ \text { L inferior frontal gyrus } & -32 & 32 & 14 & 3.22 & 0.001 & 134 \\ \text { L medial frontal gyrus } & -2 & 40 & 40 & 3.06 & 0.001 & 132 \\ \text { L cingulate gyrus } & 0 & 6 & 38 & 2.82 & 0.003 & 38\end{array}$

\begin{tabular}{lrrrrrr}
\hline Family history & & & & & & \\
L cingulate gyrus & -18 & -54 & 26 & 4.34 & $<0.001$ & 422 \\
L parahippocampal gyrus & -16 & -30 & -14 & 4.26 & $<0.001$ & 250 \\
R precuneus & 18 & -58 & 30 & 3.44 & $<0.001$ & 238 \\
L inferior parietal lobule & -48 & -26 & 26 & 3.17 & 0.001 & 115 \\
R cingulate gyrus & 16 & -10 & 42 & 3.04 & 0.001 & 73 \\
\hline
\end{tabular}

Talairach coordinates of significant voxels, at $\mathrm{p}<0.005$ uncorrected. Threshold value $=30$ voxels. $R=$ Right hemisphere; $L=$ left hemisphere.

tiple comparisons, was considered significant. The extension threshold was set at 30 contiguous voxels.

\section{Results}

One hundred and forty-five FTLD patients (103 bvFTD, 31 PNFA, 11 SD) were considered in the present study. The mean age of the FTLD group was 65.2 years, $50.3 \%$ of the patients were female, the mean years of schooling was 7.6 years, and $44.1 \%$ of patients had a positive $\mathrm{FH}$, herein considered as a marker of genetic loading. Thirteen patients carrying Granulin mutations were identified (5 bvFTD and 8 PNFA); all these cases had positive $\mathrm{FH}$, and they were significantly younger compared to the rest of the patients $(58.9 \pm 5.3$ vs. $65.8 \pm$ $7.6, \mathrm{p}<0.001)$.

The mean educational level was $7.4 \pm 3.5$ (range 3-21 years) in the $\mathrm{FH}$ - group and $7.9 \pm 3.7$ (range $4-19$ years) in $\mathrm{FH}+$ group $(\mathrm{p}=0.40)$. In E-group, $36.5 \%$ of patients had a positive $\mathrm{FH}$, whereas in the E+ group $42.3 \%$ of patients had a positive family history $(\mathrm{p}=0.50)$.

The cerebral perfusion assessment in the whole FTLD group revealed a significant frontotemporal reduction as compared to a group of age-matched controls (data not shown).

The main effect of $\mathrm{E}$ was represented by greater hypoperfusion in frontal regions in $\mathrm{E}+$ versus $\mathrm{E}-$ group (table 1; fig. 1a). The inverse relationship did not show any voxel above the pre-established threshold.

Moreover, we tested the effect of E on rCBF in Primary Progressive Aphasia group (PNFA and SD), as this has never been reported. As depicted in figure $1 \mathrm{~b}$, the same hypoperfusion pattern was evident, with a major involvement of the dominant hemisphere.

The main effect of FH was represented by a greater bilateral temporo-parietal hypoperfusion in $\mathrm{FH}+$ as compared to $\mathrm{FH}-$ (table 1; fig. 1c). The inverse relationship did not show any voxel in frontal-temporal regions at the pre-established threshold.

The main effect of $\mathrm{E}$ on $\mathrm{rCBF}$ after correction for $\mathrm{FH}$ presents only a slight reduction of the dimension of the clusters defined above (data not shown).

The analysis of covariance showed an additive effect of $\mathrm{E}$ and $\mathrm{FH}$ in right frontal lobe $(\mathrm{x}, \mathrm{y}, \mathrm{z}=+30,+40,+12$, $\mathrm{T}=3.11, \mathrm{p}<0.001$ ) (fig. 2).

Linear regression analysis between $\mathrm{rCBF}$ and $\mathrm{E}$ between $\mathrm{FH}-$ and $\mathrm{FH}+$ subgroups showed a different pattern of hypoperfusion in cognitive reserve regions on the basis of genetic loading, but always involving frontal regions (table 2; fig. 3a). The difference of slope analysis, showed a greater correlation between higher $\mathrm{E}$ and lower perfusion in the cingulate region in $\mathrm{FH}+$ as compared to FH- (table 2; fig. 3b). The inverse relationship did not show any voxels in frontal regions at the pre-established threshold.

\section{Discussion}

The high incidence of positive family history in FTLD, the relatively young disease onset in most of the cases, and the identification of a number of genes associated with inherited autosomal-dominant disorder have underlined the crucial role played by genetic background in the disease pathogenesis, although a relationship between family history and genetic background cannot be considered as unique. As a consequence, the effect of modifiable disease factors has been largely neglected. In a still orphan disease, identifying possible compensatory mechanisms and establishing whether these are modulated by genetic loading might open new avenues in defining treatment approaches.

It has been widely demonstrated that in other neurodegenerative diseases, including Alzheimer disease (AD), the educational level and the occupation status contribute to cognitive reserve; the higher the environmental attainments the greater the compensative mechanisms to cope 

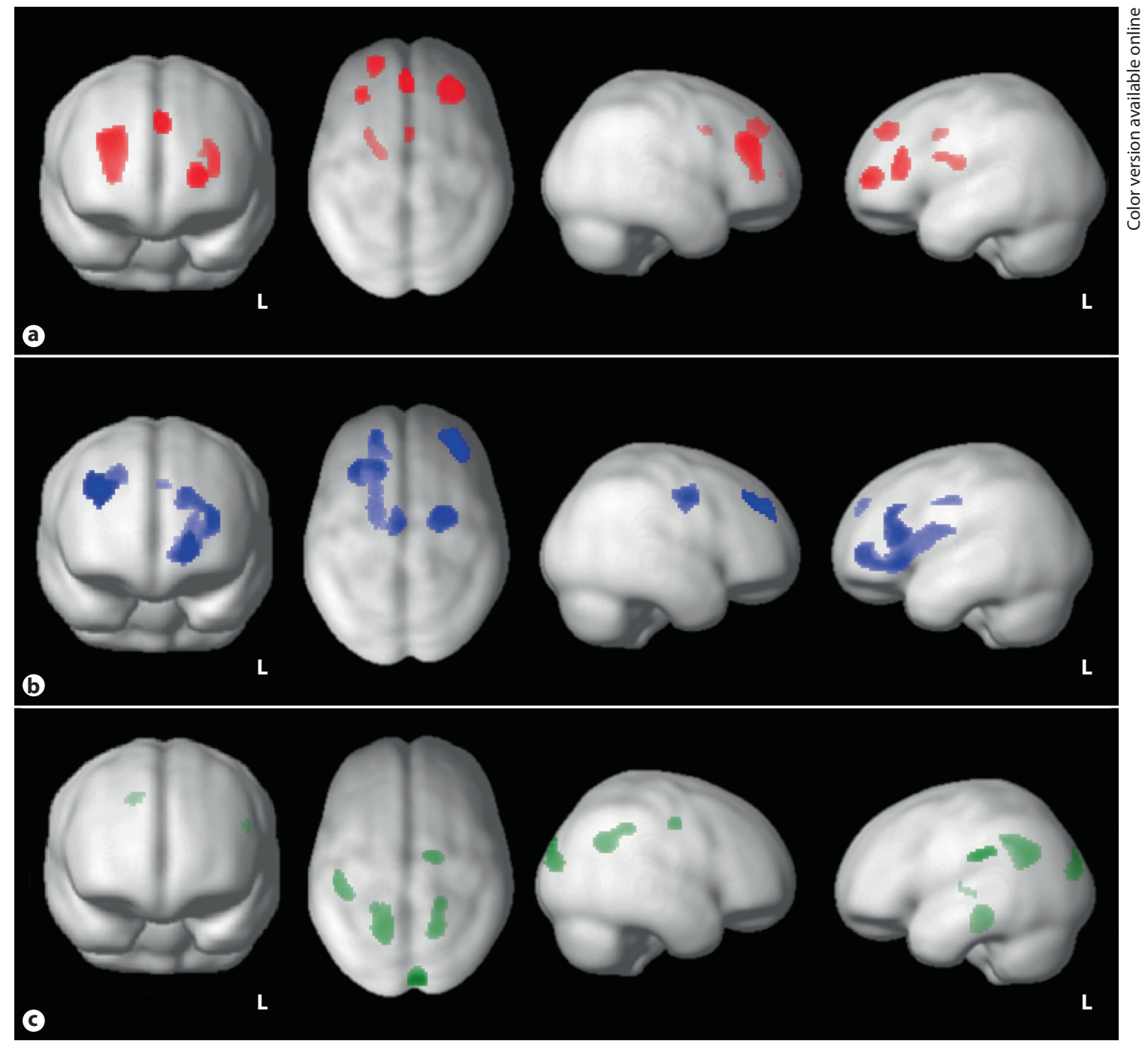

Fig. 1. The main effect of education (E+ $<\mathrm{E}-)$ in all FTLD patients (a) and in PPA patients (b), and the main effect of family history $(\mathrm{FH}+<\mathrm{FH}-)$ (c) on $\mathrm{rCBF}$ in FTLD patients, superimposed on a $3 \mathrm{D}$ brain template. $\mathrm{p}<0.005$ uncorrected, threshold $=30$ voxels.

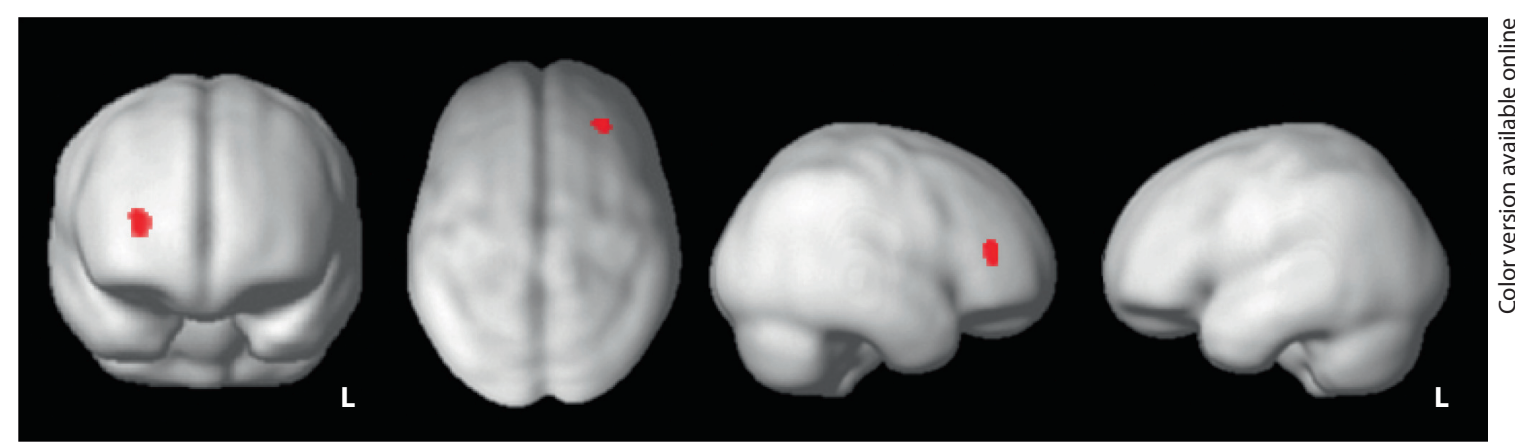

Fig. 2. Residual main effect of education $(\mathrm{E}+<\mathrm{E}-)$ in FTLD patients after covariation for family history, superimposed on a $3 \mathrm{D}$ brain template. $\mathrm{p}<0.005$ uncorrected, threshold $=30$ voxels. 
Table 2. Results of linear regression analysis between $\mathrm{rCBF}$ and education in $\mathrm{FH}-$ and $\mathrm{FH}+$ groups, respectively, and the difference of slope between the $\mathrm{FH}+$ and $\mathrm{FH}$ - groups

\begin{tabular}{lrrrrrr}
\hline & $\mathrm{x}$ & $\mathrm{y}$ & $\mathrm{z}$ & $\mathrm{T}$ & $\mathrm{p}$ & $\begin{array}{l}\text { Cluster } \\
\text { size }\end{array}$ \\
\hline FH-group & & & & & & \\
L inferior frontal gyrus & -28 & 2 & 24 & 2.77 & 0.003 & 225 \\
L inferior frontal gyrus & -32 & 30 & 14 & 3.02 & 0.002 & 139 \\
L medial frontal gyrus & 28 & 40 & 12 & 1.97 & 0.025 & 54 \\
L superior frontal gyrus & -22 & 50 & 6 & 1.96 & 0.026 & 55 \\
\hline FH+ group & & & & & & \\
L medial frontal gyrus & -22 & 50 & 10 & 2.84 & 0.003 & 225 \\
L medial frontal gyrus & -4 & 36 & 44 & 2.55 & 0.006 & 223 \\
L cingulate gyrus & -2 & 2 & 40 & 2.53 & 0.006 & 277 \\
\hline Difference of slope & & & & & & \\
L cingulate gyrus & -2 & 0 & 44 & 2.21 & 0.014 & 144 \\
\hline
\end{tabular}

Talairach coordinates of significant voxels, at $\mathrm{p}<0.05$ uncorrected. Threshold value $=30$ voxels. $R=$ Right hemisphere; $L=$ left hemisphere.

with disease onset and progression [19-21]. At the same disease stage, $\mathrm{AD}$ patients with higher education levels had greater damage in those brain areas typically affected by the disease pathology $[22,23]$. A recent study has also shown that the reserve phenomenon might compensate the unfavorable apolipoprotein epsilon 4 allele in $\mathrm{AD}$, the most recognized genetic risk factor [24].

Previous reports showed that the cognitive reserve hypothesis is confirmed in FTLD as well $[9,11]$. Accordingly, the present work further confirmed in a larger sample of patients that a greater hypoperfusion in frontal regions is consistently found in high-educated patients, as an index of the compensative mechanisms that work against the pathological process (fig. 1a). Interestingly, a similar pattern of cognitive reserve, but with a left predominance, was evident considering the subgroup of patients with primary progressive aphasia, claiming for the presence of cognitive reserve mechanisms in the whole of the FTLD spectrum (fig. 1b).

If in $\mathrm{AD}$ the reserve hypothesis has been almost studied on its own, in FTLD the assessment of the crucial weight determined by genetic background is mandatory to elucidate the interaction between nature versus nurture in the modulation of disease onset and progression.

In this view, beyond cognitive reserve effect exerted by education, our study revealed a main effect of high genetic loading (represented by positive family history) on temporal and parietal regions (fig. 1c). This is in accordance with literature data that showed a more widespread involvement of grey and white matter structures [25-27] and an extension of damage in parietal and posterior temporal regions in patients with familial disease due to pathogenic mutations, i.e. Granulin mutations [28, 29].

More interestingly, the present work evaluated how education and genetic background interact in affecting disease. The presence of a residual cognitive reserve in frontal regions after correction for family history was observed, suggesting that high education can counteract an unfavorable genetic background. Moreover, an additive effect between the two factors in the right frontal lobe was demonstrated, arguing that this region is likely the most vulnerable when this disorder is overt (fig. 2). However, as demonstrated by the analysis of the difference of slope, the presence of genetic background might modulate the distribution of the cognitive reserve, with a greater involvement of the mesial frontal regions, i.e. anterior cingulate cortex, in those patients with higher genetic loading (fig. 3). The anterior cingulate cortex is affected in FTLD [30], and this type of damage has been demonstrated in monogenic forms as well $[31,32]$. Indeed, the specific involvement of this high-connected brain structure may argue for a role of genetic background in maintaining cognitive reserve by activating different functional networks and in modulating the efficiency of the recruited neuronal networks [33-35] to obtain the resultant neural compensation.

In conclusion, our findings support the idea that reserve mechanisms may overcome genetic status, representing a potential therapeutic approach for modifying natural disease course.

\section{Acknowledgements}

The authors wish to thank patients and their families for participating in the study. We are thankful to Dr. Andrea Pilotto for helpful assistance in the discussion of the results. 


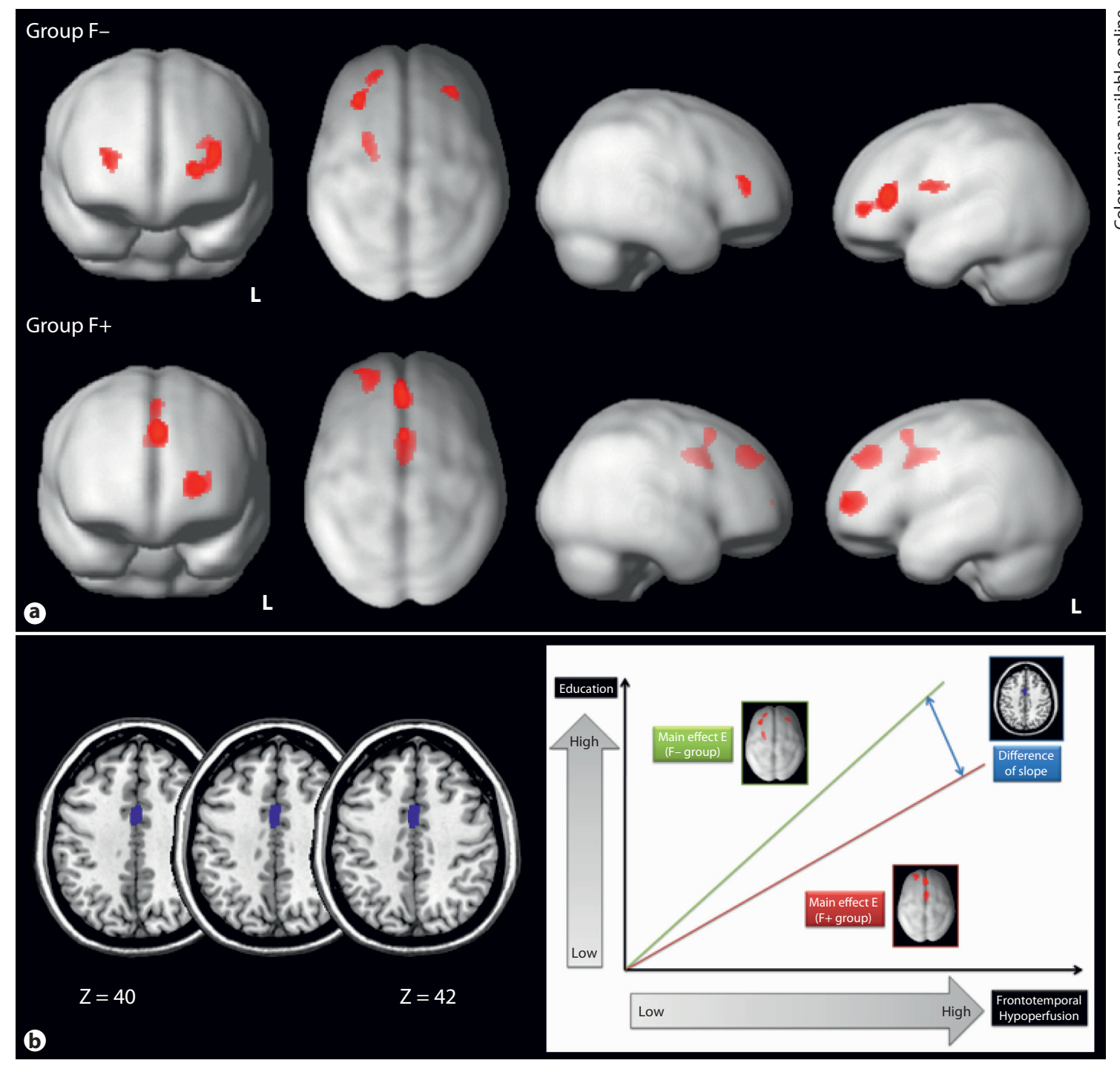

Fig. 3. Results of linear regression analysis between $\mathrm{rCBF}$ and education in the FH- and FH+ groups, respectively (a); test of the difference of slope between $\mathrm{FH}+$ and $\mathrm{FH}$ - groups (left), explicative panel of difference of slope analysis (right) (b), superimposed on a 3D brain template. $\mathrm{p}<0.05$ uncorrected, threshold $=30$ voxels.

\section{References}

$\rightarrow 1$ Neary D, Snowden JS, Gustafson L, Passant U, Stuss D, Black S, Freedman M, Kertesz A, Robert PH, Albert M, Boone K, Miller BL, Cummings J, Benson DF: Frontotemporal lobar degeneration: a consensus on clinical diagnostic criteria. Neurology 1998;51: 1546-1554.

-2 Pasquier F, Lebert F, Lavenu I, Guillaume $\mathrm{B}$ : The clinical picture of frontotemporal dementia: diagnosis and follow-up. Dement Geriatr Cogn Disord 1999;10(suppl 1): $10-14$.
-3 Seelaar H, Rohrer JD, Pijnenburg YA, Fox NC, van Swieten JC: Clinical, genetic and pathological heterogeneity of frontotemporal dementia: a review. J Neurol Neurosurg Psychiatry 2011;82:476-486.

$\checkmark 4$ Borroni B, Grassi M, Archetti S, Papetti A, Del BR, Bonvicini C, Comi GP, Gennarelli M, Bellelli G, Di LM, Padovani A: Genetic background predicts poor prognosis in frontotemporal lobar degeneration. Neurodegener Dis 2011;8:289-295.
5 Borroni B, Perani D, Agosti C, Anchisi D, Paghera B, Archetti S, Alberici A, Di LM, Padovani A: Tau haplotype influences cerebral perfusion pattern in frontotemporal lobar degeneration and related disorders. Acta Neurol Scand 2008;117:359-366.

-6 Borroni B, Ghezzi S, Agosti C, Archetti S, Fenoglio C, Galimberti D, Scarpini E, Di LM, Bresolin N, Comi GP, Padovani A, Del BR: Preliminary evidence that VEGF genetic variability confers susceptibility to frontotemporal lobar degeneration. Rejuvenation Res 2008;11:773-780. 
7 Padovani A, Cosseddu M, Premi E, Archetti S, Papetti A, Agosti C, Bigni B, Cerini C, Paghera B, Bellelli G, Borroni B: The speech and language FOXP2 gene modulates the phenotype of frontotemporal lobar degeneration. J Alzheimers Dis 2010;22:923-931.

-8 Premi E, Pilotto A, Alberici A, Papetti A, Archetti S, Seripa D, Daniele A, Masullo C, Garibotto V, Paghera B, Caobelli F, Padovani A, Borroni B: FOXP2, APOE, and PRNP: new modulators in primary progressive aphasia. J Alzheimers Dis 2012;28:941-950.

9 Borroni B, Premi E, Agosti C, Alberici A, Garibotto V, Bellelli G, Paghera B, Lucchini S, Giubbini R, Perani D, Padovani A: Revisiting brain reserve hypothesis in frontotemporal dementia: evidence from a brain perfusionstudy.DementGeriatrCognDisord 2009;28:130-135.

10 Spreng RN, Drzezga A, Diehl-Schmid J, Kurz A, Levine B, Perneczky R: Relationship between occupation attributes and brain metabolism in frontotemporal dementia. Neuropsychologia 2011;49:3699-3703.

-11 Perneczky R, Diehl-Schmid J, Drzezga A, Kurz A: Brain reserve capacity in frontotemporal dementia: a voxel-based ${ }^{18} \mathrm{~F}$-FDG PET study. Eur J Nucl Med Mol Imaging 2007;34: 1082-1087.

12 Rascovsky K, Hodges JR, Knopman D, et al: Sensitivity of revised diagnostic criteria for the behavioural variant of frontotemporal dementia. Brain 2011;134:2456-2477.

13 Gorno-Tempini ML, Hillis AE, Weintraub S, Kertesz A, Mendez M, Cappa SF, Ogar JM, Rohrer JD, Black S, Boeve BF, Manes F, Dronkers NF, Vandenberghe R, Rascovsky K, Patterson K, Miller BL, Knopman DS, Hodges JR, Mesulam MM, Grossman M: Classification of primary progressive aphasia and its variants. Neurology 2011;76:1006-1014.

14 Borroni B, Brambati SM, Agosti C, Gipponi S, Bellelli G, Gasparotti R, Garibotto V, Di LM, Scifo P, Perani D, Padovani A: Evidence of white matter changes on diffusion tensor imaging in frontotemporal dementia. Arch Neurol 2007;64:246-251.

15 Borroni B, Agosti C, Premi E, Cerini C, Cosseddu M, Paghera B, Bellelli G, Padovani A: The FTLD-modified Clinical Dementia Rating scale is a reliable tool for defining disease severity in frontotemporal lobar degeneration: evidence from a brain SPECT study. Eur J Neurol 2010;17:703-707.

- 16 Borroni B, Alberici A, Agosti C, Premi E, Padovani A: Education plays a different role in frontotemporal dementia and Alzheimer's disease. Int J Geriatr Psychiatry 2008;23: 796-800.
-17 Maldjian JA, Laurienti PJ, Kraft RA, Burdette JH: An automated method for neuroanatomic and cytoarchitectonic atlas-based interrogation of fMRI data sets. Neuroimage 2003;19:1233-1239.

18 Maldjian JA, Laurienti PJ, Burdette JH: Precentral gyrus discrepancy in electronic versions of the Talairach atlas. Neuroimage 2004; 21:450-455.

19 Garibotto V, Borroni B, Kalbe E, Herholz K, Salmon E, Holtoff V, Sorbi S, Cappa SF, Padovani A, Fazio F, Perani D: Education and occupation as proxies for reserve in aMCI converters and AD: FDG-PET evidence. Neurology 2008;71:1342-1349.

20 Stern Y, Alexander GE, Prohovnik I, Mayeux R: Inverse relationship between education and parietotemporal perfusion deficit in Alzheimer's disease. Ann Neurol 1992;32: 371-375.

21 Liao YC, Liu RS, Teng EL, Lee YC, Wang PN, Lin KN, Chung CP, Liu HC: Cognitive reserve: a SPECT study of 132 Alzheimer's disease patients with an education range of $0-19$ years. Dement Geriatr Cogn Disord 2005; 20:8-14.

22 Bennett DA, Wilson RS, Schneider JA, Evans DA, Mendes de Leon CF, Arnold SE, Barnes LL, Bienias JL: Education modifies the relation of $\mathrm{AD}$ pathology to level of cognitive function in older persons. Neurology 2003; 60:1909-1915.

-23 Rolstad S, Nordlund A, Eckerstrom C, Gustavsson $\mathrm{MH}$, Zetterberg $\mathrm{H}$, Wallin A: Biomarkers in relation to cognitive reserve in patients with mild cognitive impairment - proof of concept. Dement Geriatr Cogn Disord 2009;27:194-200.

24 Garibotto V, Borroni B, Sorbi S, Cappa SF, Padovani A, Perani D: Education and occupation provide reserve in both ApoE epsilon4 carrier and noncarrier patients with probable Alzheimer's disease. Neurol Sci 2011 Dec 16. [Epub ahead of print].

25 Borroni B, Alberici A, Premi E, Archetti S, Garibotto V, Agosti C, Gasparotti R, Di LM, Perani D, Padovani A: Brain magnetic resonance imaging structural changes in a pedigree of asymptomatic progranulin mutation carriers. Rejuvenation Res 2008;11:585-595.

-26 Beck J, Rohrer JD, Campbell T, Isaacs A, Morrison KE, Goodall EF, Warrington EK, Stevens J, Revesz T, Holton J, Al-Sarraj S, King A, Scahill R, Warren JD, Fox NC, Rossor MN, Collinge J, Mead S: A distinct clinical, neuropsychological and radiological phenotype is associated with progranulin gene mutations in a large UK series. Brain 2008; 131:706-720.
27 Zhang Y, Schuff N, Du AT, Rosen HJ, Kramer JH, Gorno-Tempini ML, Miller BL, Weiner MW: White matter damage in frontotemporal dementia and Alzheimer's disease measured by diffusion MRI. Brain 2009;132: 2579-2592.

28 Whitwell JL, Jack CR Jr, Boeve BF, Senjem ML, Baker M, Rademakers R, Ivnik RJ, Knopman DS, Wszolek ZK, Petersen RC, Josephs KA: Voxel-based morphometry patterns of atrophy in FTLD with mutations in MAPT or PGRN. Neurology 2009; 72:813-820.

29 Whitwell JL, Jack CR Jr, Baker M, Rademakers R, Adamson J, Boeve BF, Knopman DS, Parisi JF, Petersen RC, Dickson DW, Hutton ML, Josephs KA: Voxel-based morphometry in frontotemporal lobar degeneration with ubiquitin-positive inclusions with and without progranulin mutations. Arch Neurol 2007;64:371-376.

30 Allman JM, Tetreault NA, Hakeem AY, Manaye KF, Semendeferi K, Erwin JM, Park S, Goubert V, Hof PR: The von Economo neurons in the frontoinsular and anterior cingulate cortex. Ann NY Acad Sci 2011;1225: 59-71.

31 Whitwell JL, Josephs KA, Avula R, Tosakulwong N, Weigand SD, Senjem ML, Vemuri P, Jones DT, Gunter JL, Baker M, Wszolek ZK, Knopman DS, Rademakers R, Petersen RC, Boeve BF, Jack CR Jr: Altered functional connectivity in asymptomatic MAPT subjects: a comparison to bvFTD. Neurology 2011;77:866-874.

32 Matsuwaki T, Asakura R, Suzuki M, Yamanouchi K, Nishihara M: Age-dependent changes in progranulin expression in the mouse brain. J Reprod Dev 2011;57: 113-119.

33 Sumowski JF, Wylie GR, Deluca J, Chiaravalloti $\mathrm{N}$ : Intellectual enrichment is linked to cerebral efficiency in multiple sclerosis: functional magnetic resonance imaging evidence for cognitive reserve. Brain 2010;133: 362-374.

34 Stern Y, Zarahn E, Habeck C, Holtzer R, Rakitin BC, Kumar A, Flynn J, Steffener J, Brown T: A common neural network for cognitive reserve in verbal and object working memory in young but not old. Cereb Cortex 2008;18:959-967.

35 Stern Y:Cognitive reserve. Neuropsychologia 2009;47:2015-2028. 